\title{
Determinación de inmunoglobulinas $M$ en 129 recién nacidos normales de Santiago.
}

\author{
Jaime Lorca, ${ }^{1}$ Clara Rebamal, 2 Myriam Lorea, ${ }^{3}$, Guillermo Lema,' Erica Thiermann. ${ }^{3}$
}

\author{
ABSTRACT \\ Determination of inmunoglobuline $M$ in 129 nomnal newborns in Santiggo.
}

\begin{abstract}
Cuantitative deternination of total IgM, by the radial inmunodiffusion technique, was performed in 129 cord sera from full-term, normal infants in Santiago. The results obtained varied in amounts from 0 to 138 mgs $\%$. A statistical analysis, covering $80 \%$ of the sample, gave a $\mathrm{P}_{10}$ of $3 \mathrm{mgs} \%$ and a $\mathrm{P}_{\mathrm{co}}$ of $36 \mathrm{mgs} \%$, with a mean value of $11 \mathrm{mgs} \%$. Acoording to these vesults, $30 \mathrm{mgs} \%$ is suggested to be considered as cut off for elevated IgM values in cord sera in this population group.

Cuantitation of cord serum IgM is of considerable value as a screening method to detect newboms who are at risk for intenterine infection; however, additional, specific technique should be employed to establish a definitive diagnosis.
\end{abstract}

El diagnóstico de las infecciones por virus, protozoos o treponemas, trasmitidas por vías trasplacentarias suele ser difícil, especialmente en aquellos casos que no se manifiestan clínicamente en el momento del nacimiento, sino en etapas posteriores de la vida. Es innegable el valor del reconocimiento precoz de estas infecciones para instaurar el tratamiento especifico.

El diagnóstico directo, con el aislamiento o la demostración de] agente causal, suele ser diffcil y las técnicas empleadas para este objeto son en general de bajo rendimiento. De allí los esfuerzos de los investigadores por buscar métodos indirectos, mediante técnicas inmunobiológicas, que pongan de manifiesto la presencia de anticuerpos en el recién nacido.

El estudio serológico se basa habitualmente en métodos que detectan anticuerpos de tipo Ig $G$; sin embargo, la interpretación de dichos resultados en sangre de cordón se complica debido al pasaje de los anticuerpos $\mathrm{Ig} \mathrm{G}$ matemos al feto. La distinción entre anticuerpos Ig $G$ matemos y los

1 Alumnos 7. año de Medicina. Facultad de Medicina, Sede Santiago Sur, Universidad de Chile.

2 Unidad de Parasitologia, Depto. Salud Pública. Facultad de Medicina, Sede Santiago Oriente, Universidad de Chile.

3 Unidad de Parasitologfa, Depto. Medicina y Preclínicos. Facultad de Medicina, Sede Santiago Oecidente, Universidad de Chile.

Trabajo financiado en parte por el Proyecto M-022-792 del Servicio de Desarrollo Cientifico, Artístico y de Cooperación Intemacional de la Universidad de Chile. producidos por el niño, puede lograrse sólo mediante repetición sucesiva del examen serológico durante los primeros meses de la vida. Con el fin de lograr un diagnóstico más precoz de las infecciones perinatales en los recién nacidos, se recurre al estudio de las inmunoglobulinas M. Esta macroglobulina no atraviesa la placenta intacta y su presencia en la sangre de cordón se debe normalmente a una respuesta inmune del feto.

El feto es capaz de producir inmunoglobulinas con sus propios órganos linfáticos a partir de la $11 .^{\text {a }}$ semana de la gestación ${ }^{1}$ y un estímulo antigénico excesivo, producido por un agente patógeno, ya sea bacteriano, viral o parasitario, aumenta los anticuerpos de tipo Ig M a niveles patológicos. ${ }^{2}$ Esta respuesta inmune es detectable ya sea determinando la cantidad de Ig M total por $100 \mathrm{~m}] \mathrm{de}$ sangre o al demostrar la presencia de anticuerpos (Ig M) especificos contra diferentes agentes infecciosos. La cuantificación de la Ig M total en sangre de cordón constituye una prueba inespecífica útil para pesquisar aquellos casos que por presentar valores elevados de Ig $\mathbf{M}$ podrian corresponder a infecciones congénitas.

Para poder apreciar el valor diagnóstico de la cantidad de Ig $\mathbf{M}$ total en sangre de cordón debe establecerse previamente el nivel que alcanzan estas inmunoglobulinas en los reciên nacidos sanos de la misma región. Estos valores "normales" pueden estar influidos por factores biológicos propios del ambiente y por factores técnicos, relacionados con el método empleado para su cuanti- 
ficación. La utilidad de disponer de un patrón, basado en resultados obtenidos en nuestro medio, nos indujo a investigar el nivel de la $\mathrm{Ig} \mathrm{M}$ en recién nacidos aparentemente sanos de Santiago de Chile.

\section{MATERIAL Y METODOS}

El material en estudio consta de 129 muestras de sangre de cordón, correspondientes a recién nacidos de término sanos, según examen neonatologico provenientes de la maternidad del Hospital Paula Jaraquemada de Santiago.

La determinación cuantitativa de $\mathbf{I g} \mathbf{M}$ total se realizó mediante la técnica de inmunodifusión radial, de Mancini, ${ }^{3}$ modificada, empleando como soporte agarosa al $1,25 \%$, antisuero monoespecífico anti-Ig $M$ y suero control estandarizado, del Instituto de Salud Pública. Para la cuantificación se colocaron 5 lambdas de los sueros en estudio y la lectura se efectuó a las 24 horas.

\section{FESULTADOS}

Como puede observarse en la Tabla 1, cerca de la mitad de los casos $(48,8 \%)$ presentaron concen- traciones entre 0 y $10 \mathrm{mg} \%$ de Ig $\mathbf{M}$ total; en aproximadamente dos tercios $(69 \%)$ hubo valores inferiores a $20 \mathrm{mg} \%$ y en el $85,6 \%$ de los casos los resultados no sobrepasaron $\operatorname{los} 30 \mathrm{mg} \%$. Se observaron valores entre 31 y $40 \mathrm{mg} \%$ en 11 casos y de 41 a $138 \mathrm{mg} \%$ en los 8 restantes.

El análisis estadístico para esta muestra (Figura 1), que sigue una distribución asimétrica, se efectuó en percentiles cubriendo el $80 \%$ de la muestra. En esta forma, los límites de variación normal de $\lg \mathrm{M}\left(\mathrm{P}_{10}\right.$ y $\left.\mathrm{P}_{90}\right)$ son de 3 y $36 \mathrm{mg} \%$, respectivamente, con una mediana de $11 \mathrm{mg} \%$.

\section{Tabla 1}

Distribución de las concentraciones de Ig M total en 129 muestras de sangre de cordón.

\begin{tabular}{lcc}
\hline $\mathrm{mg} / 100 \mathrm{~m}]$ & $\begin{array}{c}\text { Total } \\
\text { muestras }\end{array}$ & Porcentajes \\
\hline $0-10$ & 63 & 48,8 \\
$0-20$ & 89 & 69,0 \\
$0-30$ & 110 & 85,6 \\
$0-40$ & 121 & 94,16 \\
$41-138$ & 8 & - \\
\hline
\end{tabular}

\section{DISTRIBUCION DE LOS VALORES DE CUANTIFICACION DE IgM EN 129 MUESTRAS DE SANGRE DE CORDON}

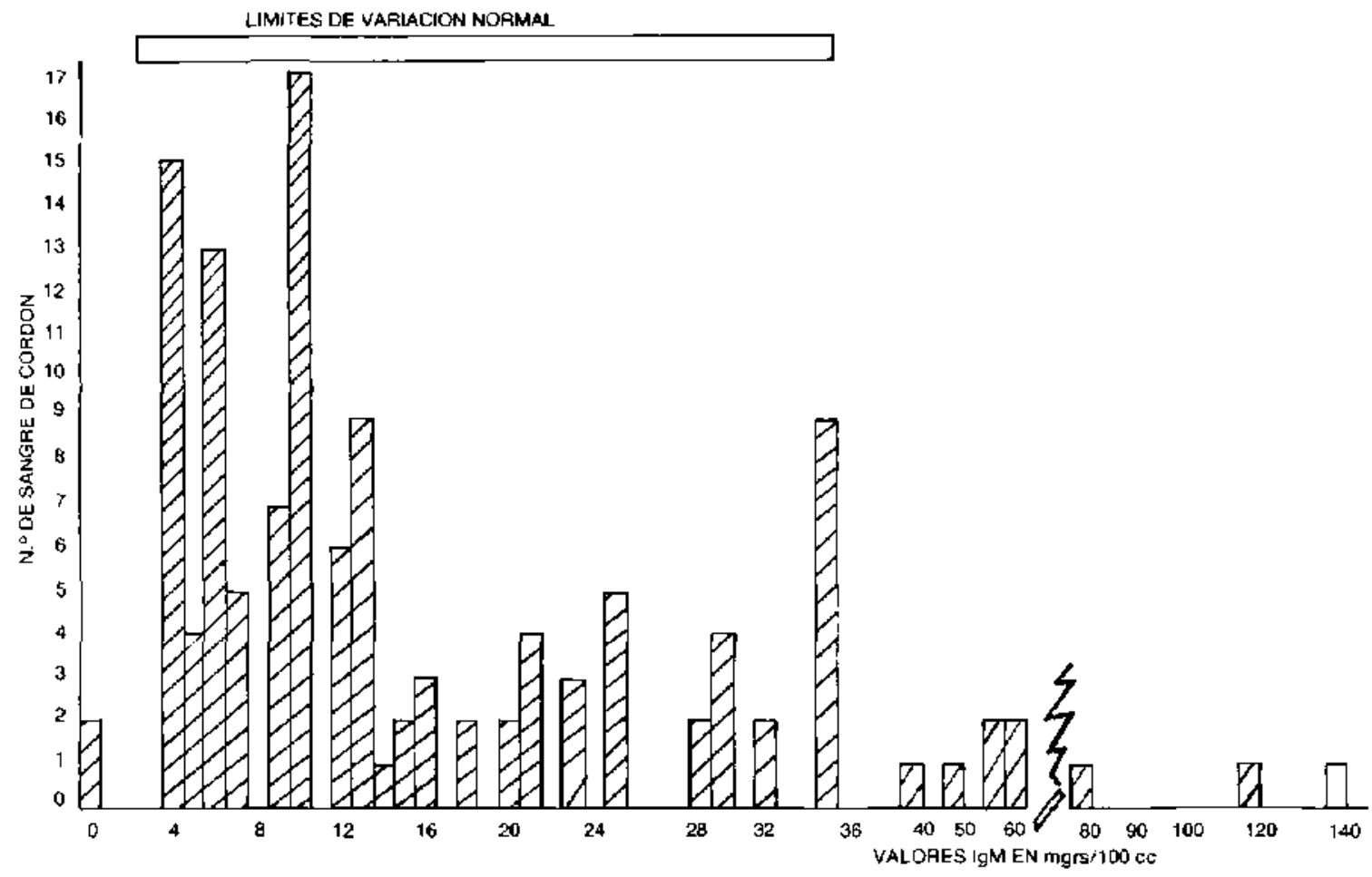




\section{DISCUSION}

Nuestros resultados confirman que las determinaciones de Ig M total, en sangre de cordón de niños aparentemente sanos, presentan una amplia gama de valores y que los niveles de Ig $\mathbf{M}$ observados en niños normales suelen ocultar a aquellos descritos en casos patológicos. ${ }^{4}$ Para utilizar esta prueba con fines diagnósticos, se debe fijar un valor límite entre Ig M "normal" e Ig M elevada. Este valor arbitrario debe alcanzar un nivel que permita pesquisar el mayor número posible de casos patológicos, evitando, a la vez, que se incluya un exceso de casos normales. La mayoría de los autores extranjeros han fijado el límite normal de Ig M en sangre de cordón, entre 18 y 20 mg \%; ${ }^{4}$ sin embargo, otros lo elevan a $30 \mathrm{mg} \%{ }^{5}$ Los resultados obtenidos en nuestro estudio indican que en nuestro media y utilizando la técnica elegida para este trabajo, 90 de cada 100 recién nacidos normales presentarían niveles de Ig $\mathbf{M}$ que oscilarían entre 0 y $36 \mathrm{mg} \%$, con un valor medio de $11 \mathrm{mg} \%$. De acuerdo con lo expuesto, aconsejamos considerar como Ig $\mathbf{M}$ elevada todo valor cyue exceda los $30 \mathrm{mg} \%$.

En el grupo de las 129 muestras de sangre de cordón que componen el presente estudio, se observaron niveles de Ig M superiores a $30 \mathrm{mg} \%$ en 19 casos, de los cuales 8 correspondieron a valores de 41 a $138 \mathrm{mg} \%$. Obviamente, estos resultados no permiten deducir que la totalidad de dichos casos correspondan a infecciones perinatales. En primer lugar, debe descartarse la posibilidad de que el resultado observado en sangre de cordón se deba a la presencia de $\mathbf{I g} \mathbf{M}$ de origen matemo, debido a una lesión de la placenta. Este factor de error puede descartarse mediante exámenes adicionales. ${ }^{6}$ Además, las infecciones intrauterinas no constituyen la única causa para la producción excesiva de la Ig M fetal.

La cuantificación de la Ig M total en sangre de cordón, si bien proporciona una importante información sobre las defensas inmunitarias desarolladas durante la vida fetal, no permite establecer un diagnóstico. De allí la necesidad del estudio cuidadoso de todos los casos con Ig M elevada, que debe incluir la búsqueda de] eventual agente causal de una infección congénita, mediante técnicas específicas.

Interpretada adecuadamente, la cuantificación de la Ig M fetal constituye un aporte útil en el estudio de los recién nacidos sintomáticos; ademăs, ha sido empleada con exito, como prueba selectiva, en la pesquisa precoz de aquellas infecciones perinatales que no se manifiestan clínicamente en el momento del nacimiento. Es asi como Alford, ${ }^{4}$ en un total de 123 recién nacidos aparentemente sanos, y que en un estudio selectivo previo habían presentado valores elevados de $\operatorname{Ig} \mathbf{M}$, encontuó 42 infecciones congénitas por diferentes microorganismos.

\section{RESUMEN}

En 129 muestras de sangre de cordón. correspondientes a recién nacidos aparentemente normales, se practicó determinación cuantitativa de Ig M total, mediante técnica de inmunodifusión radial. Los resultados obtenidos oscilaron entre 0 y $138 \mathrm{mg} \%$ y un análisis estadístico, que cubrío el $80 \%$ de las muestras, dio un $\mathbf{P}_{10}$ de $3 \mathrm{mg} \%$ y un $\mathbf{P}_{80}$ de $36 \mathrm{mg} \%$, con una media de $11 \mathrm{mg} \%$. De acuerdo con estos resultados, en nuestro medio se recomienda considerar como Ig M elevada, en sangre de cordón, todo valor que exceda los $30 \mathrm{mg}$ $\%$.

La cuantificación de Ig $\mathrm{M}$ en sangre de cordón constituye un método útil para la pesquisa de los recién nacidos con riesgo de infección congénita; sin embargo, en aquellos casos con Ig M elevada deben aplicarse técniças adicionales, especificas, que permitan establecer el diagnóstico definitivo.

\section{REFERENCLAS}

I Stetes, D.P. $y$ Calduell, J.L. Phylogeny and Ontology of the Imnune Response, in Basic and Clinical Immunology. Fundenberg. H.H.; Stetes, D.F., Caldwell, J.L. and Wells, J.V. Edit. Lange Med. Pub., 1976.

2 Alford, C.A.; Foft, J.W.; Blanquenship. WJ.; Cassady, G. y Henton, J.W. Subclinical Central Nervous System Disease of Neonates: A prospective study on infants born with increased levels of Ig M. J. Pediat 75: 1167, 1969.

3 Mancini, G.; Carbonaru, $O$. and Hermans, J.F. Inmunochemical quantification of antigens by single radial immunodiffussion. Imm. Chemistr. 2: 471, 1965.

4 Alford, C.A. Immunuglobulin determination in the diagnosis of fetal infection. Pediatr. Clinic of North Ann. 18: 99. 1971.

5Stiem, E.R. \& Furdenbers, H.H. Serum levels of inmune globut lins in health and disease. Pediat. 37: 715, 1966.

6 Miller, M.J; Surshine, Ph. J. y Remington, J.S. J. Pediat. 75 1287-1291, 1969. Quantitation of cord serum Ig M and Ig A as a screening procedure to detect congenital infection: results in 5,006 infants. 